\title{
Challenges being faced by women in ascending to decision making positions in the hotel sector in Zimbabwe
}

\author{
${ }^{1}$ Molline C. Mwando, ${ }^{2}$ Patrick W. Mamimine, Farayi ${ }^{3}$ P. Kanokanga, \\ ${ }^{4}$ Felistas Chimutingiza, \\ 1.3.4. Lecturers, School of Hospitality and Tourism, Chinhoyi University of Technology, Zimbabwe \\ 2. Senior lecturer, School of Hospitality and Tourism, Chinhoyi University of Technology, Zimbabwe
}

\begin{abstract}
In order for women to ascend to decision making positions first and foremost women must acknowledge that power is a contested resource and men cannot give it up on a platter. This paper explored the challenges being faced by women in ascending to decision making positions in the hotel sector in Zimbabwe. Despite an increase in the number of highly educated and professional women, the majority of them do not seem to occupy top posts in the corporate world especially in the hotel sector. An interview guide was used to gather data from a sample of 40 middle and lower level female managers. In-depth interviews were conducted with a sample of 10 respondents from top management. Both purposive and convenience sampling were used to select the participants. Research findings indicated that both male and female subordinates harboured a condescending attitude towards females in decision making positions. This primarily stemmed from the patriarchal nature of Zimbabwean society in which culture destined women to play subservient roles to men thereby 'ring-fencing' decision making as primarily a male domain. Besides the scourge of patriarchy, other critical challenges faced by women in ascending to decision making positions were power-phobia and fear of social backlash of the decision making function. Seemingly, the issue of addressing challenges to women's ascension to decision making positions in the hotel sector needs to be tackled structurally and holistically by observing Zimbabwe's constitutional provisions which places men and women at par (50-50) in all spheres of human endeavour.
\end{abstract}

Keywords: Challenges. Power phobia, social black lash, decision making positions, hotel sector

\section{Introduction}

[1] observes that the hospitality industry is a large and fast - growing service sector, with an average female participation of 55 per cent at global level. Women are employed in a wide variety of roles, including as cleaners, and kitchen staff, front line customer service workers and senior management. For years, hospitality industry experts and analysts have talked about the 'glass ceiling' that has prevented women in the field from ascending to the upper ranks of supervisory and managerial position. Closing the leadership gap between men and women is one of the central challenges of the $21^{\text {st }}$ century. To have so many talented women and so few women leaders is a cause for concern and represents a challenge to our society. "Women continue to aspire to leadership positions in all spheres of governance in both the public and the private sector," [2]. However it has not been easy. The willingness of women to be in leadership has not always translated into equal representation in hospitality leadership positions in Zimbabwe, the numbers are still low as evidenced by [3]. Although the number of female has increased, they are often named as an afterthought. Instead they have long worked in positions of de facto leadership in the hospitality industry, such as supervising or managing a family-owned business, or assuming additional responsibilities in their boss's absence instead of assuming their own positions. This imbalance prompted the researchers to investigate on some aspects of women leadership in selected hotels in Harare (Zimbabwe). According to [4] the hospitality industry "is clearly dominated by women but does not have a lot of female representation at the top". Women start careers in business and other professions with the same level of intelligence, education and commitment as men but the numbers shrink as the career path ascend to top management positions. If this left unattended it will inhibit the harnessing of human capital necessary to attain a balanced development in the hotel sector. Therefore this study sought to answer the following objectives: the first one being to assess the current status of women's access to decision making positions in the hotel sector. Secondly to explore the challenges being faced by women in ascending to decision making positions in the hotel sector. Lastly to identify strategies for facilitating women's optimum access to decisionmaking positions in the hotel sector

\section{Literature Review}

[5] notes that in as far as African culture is concerned, it is taboo for a woman to lead a society, and there are even supporting idioms and proverbs strictly on this specific issue. Thus, each sex group is taught and 
prepared separately for its future roles in terms of the curriculum that was specifically designed for that purpose. Women are taught to submit themselves to their husbands and to men in general, while men are taught that they are heads of families and also leaders of their society. [6] state that the differential stability in males and females has been interpreted as a function of traditional sex-role standards to the effect that aggressive behaviour in a boy is accepted and even positively valued whereas such behaviour is discouraged in girls. He notes the implication that this is just one of the cultural ways in which society exercises its control on its members, while at the same time unaware that it is practicing discrimination. [6] confirm the existence of stereotypes in most organisations. Minorities and women are presumed to be incompetent until proven otherwise and this is backed by lack of strong role models. It is unfortunate that prejudice, biases and stereotypes have come to assume such profound cultural dimensions, and their effects have in particular, resulted in debarring mostly women from positions of leadership and seeing men as the best leaders [3].

\subsection{Working in hospitality institutions}

The hospitality industry often refers to a broad variety of service industries including hotels, food service, casinos and tourism [7].In this study, the term hospitality industry refers to hotel organisations- both local and international. [8] observes that although jobs in the hospitality require feminine behaviour, male coded value systems such as overtime, visibility and occupational achievement are apparent. The hospitality industry is characterised by long working days, working long hours, low job security, a high need for coordination with others and shift work at irregular hours. These perceptions are shared by [1] who remarks that the hospitality sector poses particular challenges for women due to organisational structural characteristics. These include a highly variable demand cycle which imposes unsocial working hours on employees and can make shift patterns unpredictable, both of which are difficult to reconcile with family and care responsibilities. In developing countries, additional factors, such as limited education, widespread poverty, poor maternal health and lack of sex education together with socio- cultural factors have prevented women from being empowered as economic actors.

Despite all the hard work women have done in leadership, the subtle as well as blatant barriers that women face today result in a progressive loss of women at all career stages, ultimately affecting the number who are even within reach of powerful positions. [9] asserts that the glass ceiling describes, "all frustrations that working women experience at all levels" - although they can see where they want to go, they are blocked by invisible barriers from getting there. [1] postulates that the link between overall working conditions and the challenges faced by women in the hospitality sector needs to be better understood. This understanding needs to focus on the employment opportunities that the hospitality sector offers to women who, in many countries, represent a majority of workers in the sector but, at the same time, find themselves significantly under represented in higher paid and managerial positions, Nupur, Deepa and Khimya 2013. Studying the issues could allow governments and employers and workers' organisations to develop strategies which could lead to the promotion of greater gender equality.

[10] and [8] conducted research on the retention of highly educated personnel (employees who have followed a higher education programme at a Bachelor's or Master's level successfully) by the hospitality industry. From a certain age, more women than men leave the industry. In the age category $22-32$ years, approximately two thirds of the male and female alumni who started working in the industry after graduation are still working in the industry. However, in the age category $32-44$ years, significantly more women than men have left the hospitality industry: 61 per cent compared with 47 per cent [8]. Unfortunately, this is the age range in which one is expected to be finding their feet and starting to make a real impression and impact if they are a leader in the hospitality industry.

\subsection{Challenges hindering women from occupying top positions}

Many authors have researched on the challenges which most women face and this hinders their progression to decision making positions. Among the challenges cited in literature were the styles of leader, lack of assertiveness, difficulties in balancing work and home activities. Over and above gender prejudices, stereotyping and discrimination. In Africa history has it that, leadership has carried the notion of masculinity and the belief that men make better leaders than women is still common today in the African countries, [2]. Most women may face unique challenges in asserting and developing a leadership style yet leadership is a taxing job, for amongst other things it demands alertness, decisiveness, curiosity, adventure, daringness and assertiveness. Ouston 1993 in [12] laments the fact that "women have difficulty in developing an authoritative voice, they tend to be modest about their achievements and knowledge and to only speak assertively when concerned about others." Perhaps the women's lack of assertiveness on issues affecting them is a result of their inclination to be caring, loving, tolerant, sympathetic, patient, accommodative, and passionate even when events and circumstances demand otherwise. Some struggle with managing others while maintaining a "good girl" image. They don't want to be ignored, but they don't want to be seen as too pushy, either. It's a delicate balance 
to find a style that's effective and feels like a good fit. Women tend to be aggressive instead of being assertive, tend to be apologetic when they are expected to be decisive, become easily angry when they should be calm ; and tend to become negative when they should be positive. It also emerged that there exist some perceptions among men in the hospitality sector that executives had to be male and older this being caused by gender prejudices, stereotyping and discrimination, [3]. Failure to balance home and work obligations also proved to be another challenge which women working in hotels face emanating from pressure of time and the need to fulfill the multiple roles that a woman manager must fulfil as wife, mother [3], [10]. Also the fact that there is shift work in the hotel women face challenges for them to do it because at home they will be needed to fulfil their home obligations. Men find it absurd entertaining such kind of a scenario. However, a new dimension has taken place [13] in their study revealed that both men and women interviewed emphasized self-imposed barriers over workplace barriers as the major obstacles to women's advancement. Self established barriers interfere with advancement, such as unwillingness to relocate, concessions made within a spousal partnership, and traditional gender roles (Fischlmayr 2002 in [13]. When women perceive barriers to their career advancement, they tend to either exit, voice concern, or rationalize remaining on a plateau [14].

\subsection{Strategies for facilitating women's access to decision making positions}

Several strategies have been proposed in literature which can be used by women in or those in ascending to decision making positions. [15] argues that leadership development has come to a point of being too individually focused and elitist. There is a transition occurring from the old paradigm in which leadership resided in a person or role, to a new one in which leadership is a collective process that is spread throughout the networks of people. This implies that some of the challenges women leaders face in the hospitality sector can simply be overcome by manipulating the working conditions and organisational cultures and training. [16], suggest use of public social campaigns as a cure for gender equality. Employers and the government and support women's networks can be used to spearhead such kind of initiatives, [17]. For instance, one idea is that governments could provide tax incentives (payroll tax breaks) for employers that hire well-qualified women who are interested in more family or work-life flexibility such that if these women are working part-time, the business will receive a tax incentive in the form of a payroll tax break or health insurance policy reimbursement so that it does not cost a business any more to employ someone part-time employees [13] Firms can also provide women with more flexible work time and work location, as well as relocation assistance and provision of childcare [18].

\section{Methodology}

The research design was a descriptive survey. The population consisted of 118 women in managerial positions in selected hotels in Harare hotels and $42 \%$ was used as the sample. Three hotel groups were selected because of their big sizes and because they have many women occupying positions of influence. Purposive sampling was used since the study was confined to women in various managerial positions - supervisors, assistant managers, heads of departments, general managers and directors. A sample of 10 top managers and 40 middle and low level managers was used. One group had 5 top managers and 18 middle and low level managers, the other two had 3 and 2 top managers respectively and 11 middle and low level managers each. Convenience sampling was used to select the actual participants. It was necessary to probe top managers since they had the most experience in leadership and management and had faced challenges at a very high level. An interview based questionnaire was used to gather responses from middle and low level managers while an interview guide (in- depth) was applied on the top management. Exploratory data analysis- using tables and graphic displays, was utilised.

\subsection{Response rate}

\section{Findings and Discussion}

A total of 50 interviews were targeted but the researcher managed to conduct 44 interviews with respondents. Thus the response rate was $88 \%$. Respondents were asked to provide bio-data, age, marital status, education and their positions within the organization.

\subsection{Distribution of respondents by age and level of management}

Table 1 Distribution Of Respondents By Age And Level Of Management

\begin{tabular}{|l|l|l|l|l|l|l|}
\hline Age & $\mathbf{2 5}$ & $\mathbf{2 5 - 3 4}$ & $\mathbf{4 5 - 5 4}$ & $\mathbf{> 5 4}$ & $\begin{array}{l}\text { Total no of } \\
\text { respondents }\end{array}$ & $\begin{array}{l}\text { Total \% no } \\
\text { respondents }\end{array}$ \\
\hline Top Mgt & 3 & 11 & 0 & 0 & 14 & 32 \\
\hline Middle Mgt & 1 & 14 & 5 & 1 & 22 & 50 \\
\hline Top Mgt & 0 & 2 & 4 & 2 & 8 & 18 \\
\hline Total & 4 & 27 & 9 & 3 & 44 & 100 \\
\hline
\end{tabular}


A higher percentage $\%$ of respondents were concentrated at the age range 25-34 and thereafter the figure decreases. Results are contrary to a research conducted by [19] who found out that during the child bearing age fewer women are in management positions, compared to men and from 45 onwards the pattern converges again. The explanation could because of most of them would have come from university and joined a maximum of two-year management training which is offered by most Hotel groups in Zimbabwe thus landing them to be in those categories. [6] confirm that the higher a woman climbs the corporate ladder, the lonelier she gets because there is less support available. Through probing the researchers found out that out of the 44 respondents interviewed 55\% indicated to be in the single category and after probing it showed that most of the respondents in this category were singled due to divorces. $25 \%$ indicated that they were married and $20 \%$ indicated that they were widowed.

\subsection{Respondents qualifications}

The results show that $64 \%$ of the women had Bachelors degree, $30 \%$ had Diplomas while $4 \%$ of the women had A' Level Certificates and $2 \%$ had O' Levels or below. A high percentage of women that were interviewed added that they were still studying towards attaining higher qualifications, possibly not achieved due to career breaks from child rearing and lack of opportunity for advancing at an early stage. [20] indicate that eighty percent of the women's career progress relative to men's in the sector is hampered by breaks in their career due to childbirth and childcare, $[21] \&[22]$.

\subsection{Current status of women's access to decision making positions in the hotel sector}

Information gathered from secondary data source human resources personnel and students on attachment revealed that $66 \%$ of the managers are men and $33 \%$ are females. The proportion is still small as alluded to by [3] but it is encouraging that employers are seeing the importance of including women in decision making positions. This is contrary to [19] who are of the opinion that to strengthen the senior management team there is need for a more gender balanced team - a case which is growing in strength. Not only does evidence suggest that it produces real financial rewards, it also highlights the importance of having a broader representation of women. Businesses with three or more female board members have been found to deliver the biggest impact

\subsection{Challenges being faced by women in ascending to decision making positions in the hotel sector The following emerged as topical themes from the study:}

\subsubsection{Time constraints due to multiple roles}

Being a mother, wife, member of the congregation and coming to work is quite hectic. One of the respondents cited this as one of the challenges they face as women and all the women echoed the same sentiments regardless of their management levels. [20] indicate that eighty percent of the women's career progress relative to men's in the sector is hampered by breaks in their career due to childbirth and childcare , $[22] \&[23]$.

\subsubsection{Dominant masculine organisational culture}

With women traditionally being largely absent from senior management positions, organisational culture can be perceived by some as being masculine. The respondents said that a dominant male culture and attitude is a hindrance to moving up the career ladder. They seem not to have anyone to look up to because of the difference in gender obligations. There are fewer role models to emulate or learn from. Women's career progress in the sector is hampered by the existence of male culture and 'old boys network', [20]. Results also confirms the findings by [21] who carried out a study on the barriers which hinder women's career progress in Jordan.

\subsubsection{Negative attitude from subordinates}

This was quite surprising as $80 \%$ of the respondents mentioned negative attitude from subordinates from both gender but mostly from their female counterparts. This was evidenced by the comments which were given: Dealing with a human being is an issue at times when you delegate duties to your subordinates they do not perform to the required standard maybe just because I am a woman.

There are times when the male subordinates even exchange words despising your commands.

'Who is she for me to listen to her instructions she thinks wearing a pair of trousers will change her to be a man. Results reveal that female counterparts also contribute to some of the challenges female managers face. Same findings were produced by [24] in his study where female respondents described female subordinates as uncooperative, hostile, jealous, talkative and lazy. Another reason contributing to the negative attitude could be the leadership style being used by some of the managers as $44 \%$ of the respondents indicated that they solve 
some of the challenges by being autocratic. [7] noted that women tend to be tough in order to rise into the managerial ranks and they change their communication style in an effort to adapt to male-dominated hierarchical organizations. Female managers can become more direct and unresponsive to feelings, which provoke a negative evaluation, [25]. On the other hand there could be misinterpretations of actions the challenge could be one of the self imposed barriers which were referred to by [13] in their study. Patriarchal dominance can also be taking cognizance where there is general contempt of women leadership among subordinates. The overall consensus among researchers is that specific gender traits among individuals guide decision making and judgements [27]. This could be one of the contributing of the bias in the hotel sector.

\subsubsection{Element of being risk averse}

The aspect of risk averse also proved to be eminent in the female managers interviewed. The following statements were given to show that they want to be blame free or want to maintain the good girl image.

I am reluctant to take risks and always fear messing up.

We tend to be limited to go to the top because of fear of the unknown.

The majority of the respondents interviewed were very protective of themselves.

We women are very protective of ourselves and we are reluctant to take criticism or suggestions despite them being valid.

They view criticism as being looked down upon hence they do not take criticism positively in most cases, whereas [26], asserts that leadership is a taxing job, for amongst other things it demands alertness, decisiveness, curiosity, adventure, daringness and assertiveness. This leaves women to find themselves on a 'glass-cliff' than their male counterparts, such that their position of leadership is risky or precarious, [21]

\subsubsection{Nature of women and the nature of the job itself}

The so called nature of women and the nature of the job itself has been seen to be hampering the growth of women to leadership positions. $70 \%$ of the female managers complained about the nature of the job whereby they viewed it to be taxing and unsocial.

The working hours are not women friendly because at times you finish work at around two o'clock in the morning and by the time you get home you are very exhausted and unproductive

Being a manager in a hotel makes you antisocial as you are not able to fulfil your social obligation in the community as a friend, church mate and a neighbour.

These perceptions are shared by [1] who remarks that the hospitality sector poses particular challenges for women due to organisational and structural characteristics. [8] observes that although jobs in the hospitality require feminine behaviour, male - coded value systems such as overtime, visibility and occupational achievement are apparent which makes it difficult to reconcile with family and career responsibilities. However the other $30 \%$ had different views they accepted it as part of the game plan.

\subsubsection{Lack of time to network}

Lack of time and fear of their husbands were cited to be some of the factors which contributed to lack of networking by $75 \%$ of the married female managers. One of the respondents highlighted that

My husband is very protective of me such that mingling with the men is a no go area to him.

My schedule is very busy such that 1 find networking taking much of my time.

This mentality is in contrary to what [15] thinks about the new paradigm shift to leadership. There is a transition occurring from the old paradigm in which leadership resided in a person or role, to a new one in which leadership is a collective process that is spread throughout the networks of people. Networking is critically important in career progression, but findings suggest that women are being excluded by some critical networks and that some may lack the confidence to network.

\subsection{Strategies for facilitating women's optimum access to decision-making positions in the hotel sector}

When asked on how they deal with the challenges, $56 \%$ of respondents cited democracy in their leadership behaviour whilst $44 \%$ were for autocracy and $0 \%$ for laissez fare leadership style. When asked to justify their responses those that cited democratic leadership stated that women believe in consultation so that an objective decision is made to benefit all who will be affected by such a decision.

If you empower a woman you have empowered the nation. Women need resources; support from male counterparts in order for them to be emancipated socially, economically and politically thus will result in their success in the business world.

Women should network with other women in management to find better ways to deal with people who report to them.

The overall view was that it was a good way of finding out the capabilities of the workers and therefore know how to place them when a job needs to be done. People want to be more involved in their work places. They want to know the reason they are doing certain things. Offering time management courses, attitude 
training and communication skills training as well as performance management courses so that women leaders will be able to review performance of their subordinates based on concrete evidence and results rather than double standards which undermine the credibility of women as effective leaders. Women currently in leadership positions should groom aspiring female leaders to take up leadership positions. The researchers advocate for the need to build awareness of business education and careers among women to increase the pipeline of women entering top management positions. This can be done by encouraging parents to afford the girl child equal educational opportunities. For any programme meant to assist and help empower women to succeed, there should also be a parallel program geared at changing men's attitudes towards looking at women as inferior to them. Therefore such a program should also strive at preparing men for any cultural shock that they might experience as a result of either finding themselves being on an equal footing with women, or, under women as their leaders. Women who aspire to take up leadership positions should be adventurous, assertive and participate in meetings at work places and not undermine their contributions. They should also continuously look for opportunities to advance themselves and not be afraid to take risks. Networking has also emerged to be crucial for career progression as evidenced in the above statement

\section{Conclusion}

The study found out that the overall representation of women in leadership positions is still low in the hospitality sector, though there has been a general increase in the numbers of women who participate in leadership positions. This primarily stemmed from the patriarchal nature of Zimbabwean society in which culture destined women to play subservient roles to men thereby 'ring-fencing' decision making as primarily a male domain. Besides the scourge of patriarchy, other critical challenges faced by women in ascending to decision making positions were power-phobia and fear of social backlash of the decision making function. Overally, the bulk of the challenges are a result of women's inclination to be caring, loving, tolerant, sympathetic, patient, accommodative and passionate even when the events and circumstances demand otherwise. Further research can be conducted on comparative study of leadership aptitude between men and women with comparative job requirements in order to establish the effectiveness of cross-gender combinations in leadership.

\section{References}

[1] T. Baum, International Perspectives on Women and Work in Hotels, Catering and Tourism - Working Paper $1 / 2013$ for the International Labour Organisation (ILO 2013)

[2] J. Kiamba, Women and Leadership Positions: Social and Cultural Barriers to Success, Women Activism for Gender Equality for Africa 6 Special issue 2008

[3] A. Zinyemba A. Leadership challenges for women managers in the hospitality and financial services inZimbabwe, International Journal of Advanced Research in Management and Social Sciences 2 (4) 2013 50-57

[4] A.Davenport Tips for Maintaining Great Female Leaders, Goodwin and Associates http://www.womeninhospitality.com/articlelibrary/2008-01-15

[6] U.Sekeran, and F Leong Women Power, Managing in Times of Demographic Turbulence,( Sage Publications 1989)

[5] C. Gedney Leadership effectiveness and gender These Maxwell Air Force Base, Alabama 1999

[7] B. Brotherton, and R. Wood, (Eds) (The Sage Handbook of Hospitality Management, New York: Sage 2008)

[8] R. Blomme, A. Rheede, D. Tromp Work - Family Conflict As A Cause for Turnover Intentions in the Hospitality Industry Tourism and Hospitality Research, 10(4) 269-285 2010

[9] T. Gillen, Leadership Skills for Boosting Performance, (Chartered Institute for Personnel Development, 2002)

[10] S. Nupur, K. Deepa and T. Khimya Road to the Top- Barriers Faced by Women in the Financial Sector in Oman, Research Journal of Management Sciences 2(9), 2013 1-6

[11] K..Walsh, and M. Taylor, Developing in-house careers and retaining management talent. Cornell Hotel and Restaurant Administration Quarterly, 48(2), 163-182.2007

[12] E. Tsoka and E. Mathipa, Possible barriers to the advancement of women to leadership positions in the education profession, South African Journal of Education, 21(4) 324-331 2001,

[13] J.Boone, J. Houran, and T.Veller, Rethinking A Glass Ceiling in the Hospitality Industry, Hotel Travel and Hospitality News, September 2013

[14] S. Hamel. Exit, voice and sensemaking following psychological contract violations. Journal of Business Communication 46 (2) 2009, 234261

[15] N. Petrie Trends in Leadership Development (White Paper for Center for Creative Leadership, 2011)

[16] M.Bastounis, and J. Minibas-Poussard.. Causal attributions of workplace gender equality, just world belief, and the self/other distinction. Social Behavior and Personality 40 (3):433-52. 2012

[17] H.McCarthy , Girlfriends in high places: How women's networks are changing the workplace. London: Demos 2004

[18] C. Fogliasso, Women in management: Observations and trends. Franklin Business \& Law (1): 108. 2011

[20] P. Smith and B. Crimes,. Women in Management a Case of a "Glass Ceiling'?: An Investigation into the Relative Under-Representation of Women in Senior Management Positions in UK Travel and Tourism. The International Journal of Diversity in Organisations, Communities and Nations, 7(5), 323-331. 2007.

[21] E. Manasra, What Are the "Glass Ceiling" Barriers Effects on Women Career Progress in Jordan? International Journal of Business and Management. 8,. (6); 2013

[22] A. Miller, The Effects of Motherhood Timing on Career Path Journal of Population Economics, 24(3): 1071-1100, 2010

[23] M. Bertrand, C. Goldin, and L. Katz, "Dynamics of the Gender Gap for Young Professionals in the Financial and Corporate Sectors," American Economic Journal: Applied Economics, 2, 228-55. 2010

[24] D. Laketch, Reaching the top: Women managers in eastern and southern Africa, WID/WIM Division, Eastern and Southern African Management Institute Nairobi, Kenya, 1991

[25] R. Burke, C. McKeen, and C. McKenna,C).Correlates of mentoring in organizations:The mentor's perspective. Psychological Reports, 72, $883-896,1993$

[26] M. Ryan, and . Haslam,, The glass cliff: Evidence that women are over-represented in precarious leadership positions. British Journal of Management, 16: 81-90. .2005 